Published in final edited form as:

Nicotine Tob Res. 2016 May ; 18(5): 1116-1125. doi:10.1093/ntr/ntv145.

\title{
Smoking Patterns and Receipt of Cessation Services Among Pregnant Women in Argentina and Uruguay
}

\author{
Mabel Berrueta, MD¹, Paola Morello, MD, MPH${ }^{1}$, Alicia Alemán, MD $^{2}$, Van T. Tong, MPH $^{3}$, \\ Carolyn Johnson, $\mathrm{PhD}^{4}$, Patricia M. Dietz, $\mathrm{DrPH}^{3}$, Sherry L. Farr, $\mathrm{PhD}^{3}$, Agustina Mazzoni, \\ MD1 , Mercedes Colomar, MSc ${ }^{2}$, Alvaro Ciganda BlnfoTech², Laura Llambi, MD², Ana Becú, \\ BMid ${ }^{1}$, Luz Gibbons, MSc ${ }^{1}$, Ruben A. Smith, $\mathrm{PhD}^{3}$, Pierre Buekens, MD, PhD ${ }^{4}$, Jose M. \\ Belizán, $\mathrm{MD}, \mathrm{PhD}^{1}$, and Fernando Althabe, $\mathrm{MD}, \mathrm{MSc}^{1}$ \\ ${ }^{1}$ Department of Mother and Child Health Research, Institute for Clinical Effectiveness and Health \\ Policy (IECS), Buenos Aires, Argentina \\ ${ }^{2}$ Clinical and Epidemiological Research Unit, Montevideo, Uruguay \\ ${ }^{3}$ Division of Reproductive Health/NCCDPHP, Centers for Disease Control and Prevention, Atlanta, \\ GA \\ ${ }^{4}$ Tulane School of Public Health and Tropical Medicine, New Orleans, LA
}

\section{Abstract}

Introduction-The 5A's (Ask, Advise, Assess, Assist, and Arrange) strategy, a best-practice approach for cessation counseling, has been widely implemented in high-income countries for pregnant women; however, no studies have evaluated implementation in middle-income countries. The study objectives were to assess smoking patterns and receipt of 5A's among pregnant women in Buenos Aires, Argentina and Montevideo, Uruguay.

Methods-Data were collected through administered questionnaires to women at delivery hospitalizations during October 2011-May 2012. Eligible women attended one of 12 maternity hospitals or 21 associated prenatal care clinics. The questionnaire included demographic data, tobacco use/cessation behaviors, and receipt of the 5A's. Self-reported cessation was verified with saliva cotinine.

Results-Overall, of 3400 pregnant women, $32.8 \%$ smoked at the beginning of pregnancy; $11.9 \%$ quit upon learning they were pregnant or later during pregnancy, and $20.9 \%$ smoked throughout pregnancy. Smoking prevalence varied by country with $16.1 \%$ and $26.7 \%$ who smoked throughout pregnancy in Argentina and Uruguay, respectively. Among pregnant smokers in Argentina, $23.8 \%$ reported that a provider asked them about smoking at more than one prenatal care visit; $18.5 \%$ were advised to quit; $5.3 \%$ were assessed for readiness to quit, $4.7 \%$ were

Corresponding Author: Mabel Berrueta, MD, Department of Mother and Child Health Research, Institute for Clinical Effectiveness and Health Policy (IECS), Dr Emilio Ravignani 2024 (C1414CPT), Ciudad de Buenos Aires, Argentina. Telephone/Fax:

54-11-4777-8767 extension 48; mberrueta@iecs.org.ar.

Declaration of Interests

None declared. 
provided assistance, and $0.7 \%$ reported follow-up was arranged. In Uruguay, those percentages were $36.3 \%, 27.9 \%, 5.4 \%, 5.6 \%$, and $0.2 \%$, respectively.

Conclusions-Approximately, one in six pregnant women smoked throughout pregnancy in Buenos Aires and one in four in Montevideo. However, a low percentage of smokers received any cessation assistance in both countries. Healthcare providers are not fully implementing the recommended 5A's intervention to help pregnant women quit smoking.

\section{Introduction}

Smoking during pregnancy is associated with many adverse outcomes for both the mother and baby including placental complications, intrauterine growth retardation, low birth weight, preterm birth, stillbirth, neonatal death, reduced infant lung function, infant neurodevelopment problems, and sudden infant death syndrome. ${ }^{1-4}$ Smoking is high among women of reproductive age in Argentina (13\%-23\%) and Uruguay (16\%-22\%), 5 ,6 and prevalence of smoking during pregnancy is estimated to be $11 \%$ and $18 \%$, for Argentina and Uruguay, respectively. ${ }^{7}$ However, it is unknown what percentage of women who smoked before pregnancy quit when they learn they are pregnant or later during pregnancy and reasons why women quit in these two countries.

Some women stop smoking spontaneously when they find out they are pregnant. ${ }^{7}$ To support these women and those who cannot quit on their own, clinician counseling is recommended by the World Health Organization, ${ }^{8}$ and has been shown to modestly increase quits and reduce the risk of preterm delivery and low birth weight. ${ }^{9}$ As pregnancy is a time of frequent contact with health professionals, healthcare providers may help to improve maternal and infant health by systematically identifying and providing counseling to pregnant patients who currently or recently used tobacco. The 5A's (Ask, Advise, Assess, Assist, and Arrange) is a best-practice and evidence-based approach for delivering cessation counseling to all smokers. ${ }^{9,10}$ This strategy has been implemented in several countries, including low and middle income countries. ${ }^{11}$ Since 2011 in Argentina, ${ }^{12}$ and since 2009 in Uruguay, ${ }^{13}$ national tobacco control programs have recommended brief cessation counseling interventions based on, or equivalent to, the 5A's; however, training and resources for this approach have not been delivered to healthcare providers at a national level. Thus, it is unknown the extent to which the 5A's for smoking cessation are being implemented by prenatal care providers. The study objectives are to assess smoking patterns and describe receipt of the 5A's for smoking cessation during pregnancy among women attending prenatal care in publicly-funded clinics in Buenos Aires, Argentina and Montevideo, Uruguay. The data from the current study uses baseline data from a cluster randomizedcontrolled trial of brief counseling to help pregnant women quit smoking. Approximately, 99\% of the childbirths in these countries are attended at maternity hospitals; 70\% and 50\% of childbirths take place in publicly-funded hospitals in Argentina and Uruguay, respectively, which are funded by the ministries of health and free of charge. Prenatal care is provided by physicians and midwives, and over $94 \%$ of pregnant women receive prenatal care during at least four visits during pregnancy (a mean of seven visits). Women attending these publicly-funded centers come from the most deprived economic sectors in both 
countries. ${ }^{14,15}$ These data can be used to inform national tobacco control efforts and prenatal care practices in both countries.

\section{Methods}

\section{Data Collection}

Our study used baseline data from a cluster randomized-controlled trial prior to implementing a brief smoking cessation counseling intervention. Trial results are not yet available, but detailed methodology is published elsewhere. ${ }^{16}$ Prenatal clinics were selected for the main trial if they served more than 250 unique pregnant women per year, did not have a smoking cessation program based on the 5A's for pregnant women, and had physicians, midwives or nurses as part of their clinic staff. Women were eligible for the current study if they attended one of 21 prenatal clinic clusters and delivered in one of 10 public hospitals in the Province of Buenos Aires, Argentina or one of two hospitals in Montevideo, Uruguay, during October 2011-May 2012. Women with mental or physical impairments that prevented them from being interviewed and women with a diagnosis of stillbirth at admission to the hospital were ineligible to participate.

All consecutively eligible women who signed an informed consent were included until a sample of 100-200 women per cluster was achieved, as required for the main trial. ${ }^{13}$ Interviews were conducted face-to-face within the first 48 hours after delivery and was administered by trained interviewers. Data were collected on paper forms and entered in each country in a secure web data open source management system (OpenClinica). ${ }^{17}$

The questionnaire was adapted from a previous study on tobacco use during pregnancy conducted in Argentina, Uruguay and other countries in $2005,{ }^{7}$ additional questions were added, and questionnaire was pilot-tested again from November 2010 to February 2011. The questionnaire included questions on basic demographics, prenatal care characteristics, tobacco use and cessation behaviors, second-hand smoke exposure, and receipt of cessation counseling during the prenatal care visits.

Data collectors within 12 hours after delivery asked eligible women two questions about their smoking status and women who reported smoking cessation as soon as they found out they were pregnant or later during pregnancy were asked to provide a saliva sample Biochemical verification was not conducted among women who reported not smoking prior to pregnancy or if they continued to smoke during pregnancy, as the risk of misclassification in these groups are likely low ${ }^{18}$ Women were asked to gently chew on the cotton swab insert from a Salivette (Sarstedt, Newton, NC). The Salivettes were stored in a refrigerator at the hospital for up to 1 month, transferred to a central freezer in each country, and shipped to the US Centers for Disease Control and Prevention laboratory in Atlanta, Georgia, for analysis. Salivary cotinine was measured by high-performance liquid chromatography atmosphericpressure chemical ionization tandem mass spectrometry. ${ }^{19,20}$ After analysis was completed, the saliva samples were disposed of accordingly.

The study was approved by the ethics committees of all participating hospitals; the Ethics Committee of the Ministry of Health of the Province of Buenos Aires, Argentina; the Ethics 
Committee of the Centro de Educacion Medica e Investigaciones Clinicas "Norberto Quirno"; the Ethics Committee of the School of Medicine, Universidad de la Republica, Uruguay; and the Tulane University Institutional Review Board, United States.

\section{Variables}

Self-reported smoking during pregnancy was determined from questions about the woman's smoking status before and during pregnancy. Women's smoking status was categorized as nonsmokers, spontaneous quitters, late quitters or continued smokers. "Nonsmokers" were those who reported never smoking, tried cigarettes but did not smoke regularly, or quit smoking before they found out that they were pregnant. "Spontaneous quitters" were those who reported quitting as soon as they found out they were pregnant, were abstinent until delivery, and had saliva cotinine $\leq 10 \mathrm{ng} / \mathrm{mL}$. "Late quitters" were those who reported smoking at the time they found out they were pregnant but quit later during pregnancy and remained abstinent until delivery, and had saliva cotinine $\unlhd 10 \mathrm{ng} / \mathrm{mL} .{ }^{21}$ "Continued smokers" were those who reported smoking every day or some days throughout pregnancy or within the last week prior to delivery. Women who reported quitting during pregnancy, but whose measured cotinine was more than $10 \mathrm{ng} / \mathrm{mL}$ were also defined as continued smokers. About $10.0 \%$ of women who self-reported smoking cessation during pregnancy had biochemical evidence of continued smoking; detailed results are published elsewhere. ${ }^{22}$

All women, including nonsmokers, were asked about receipt of the first two steps of the 5A's: (1) provider screening for tobacco use (Ask) and (2) advice about the harms of tobacco use to themselves or to the unborn infant (Advise). Only quitters (spontaneous and late quitters) and continued smokers were asked about receipt of the remaining three steps of the 5A's: (3) provider assessed their readiness to quit (Assess), (4) woman received assistance from provider (Assist), and (5) provider requested a follow-up contact with woman (Arrange). Assistance could have included advice on how to decrease withdrawal symptoms, help with the process, printed materials, referral to the quitlines, ${ }^{12,13}$ or referral to a health care professional for cessation assistance. For each of the 5A's, women were asked whether it was provided at least one visit, at more than one visit or at all prenatal care visits.

Additional variables derived from the woman's interview were maternal age, citizenship, marital status, highest level of education completed, work status in past year, and trimester of prenatal care initiation. Parity was derived from the clinical record. For spontaneous quitters, late quitters, and continued smokers, we also assessed number of days smoked per week, number of cigarettes smoked per day, quitting attempts, reasons for quitting, smoking initiation prior to pregnancy and intention to use tobacco after the baby was born.

\section{Analysis}

Of 3588 eligible women who were invited to participate $4.3 \%$ did not provide consent. We excluded three women from the analysis due to missing identification number, 25 due to missing information on smoking status and five due to uncompleted Case Report Forms. The final sample included 3400 women (94.8\% of the initial sample); 1863 women (54.8\%) gave birth in Argentina and 1537 women (45.2\%) in Uruguay. We report frequencies and 
percentages for categorical variables, and median and interquartile ranges for continuous variables overall and by country. Analyses were conducted using SAS version 9.3. ${ }^{23}$

\section{Results}

Of 3400 pregnant women, most were 20-34 years old (69.0\%), citizens of Argentina or Uruguay (93.32\%), married or partnered (80.3\%), had completed at least 6 years of schooling (93.4\%), unemployed in the past year (76.4\%), multiparous (greater than one child; $64.5 \%$ ), and initiated prenatal care in the first trimester (52.3\%). Women who reported continued smoking were more likely to be single, less educated, multiparous, and living with at least one smoker compared to nonsmokers (Table 1).

Sixty-seven percent of the sample did not smoke and overall $32.8 \%$ of women were smokers at the beginning of their pregnancy. Of these, $8.3 \%$ were spontaneous quitters, $3.6 \%$ were late quitters, and $20.9 \%$ continued smokers (Table 1). Mean age of smoking initiation was similar in both countries and did not vary by group: 15.5 (3.3), 15.1 (2.6), and 15.1 (3.3) years old for spontaneous quitters, quitters during pregnancy and current smokers, respectively. Smoking prevalence varied by country, Uruguay had a higher percentage of women who smoked throughout the pregnancy compared to Argentina (26.7\% vs. $16.1 \%$; Tables 2 and 3). Overall, five out of 10 women in both countries reported living with at least one smoker. A detailed analysis of secondhand smoke exposure in this population is provided elsewhere. $^{24}$

Overall in both countries, $80.0 \%$ of nonsmokers reported that they were asked about their smoking status, and $36.8 \%$ were advised that not smoking was the best thing they could do for their baby in at least one prenatal visit. However, a lower percentage of nonsmokers received the first 2A's at more than one visit (Ask $=24.4 \%$, and Advise $=12.0 \%$ ) and at all visits (Ask $=13.3 \%$, and Advise $=5.4 \%$; data not shown). Among all quitters, 95.3\% were asked their smoking status, $62.9 \%$ were advised to quit smoking, $17.8 \%$ were assessed of their readiness, $11.9 \%$ received assistance to quit and 3.0\% received follow-up on their smoking in at least one visit. Lower percentages of quitters received each step of the 5A's at more than one visit and at all prenatal visits (Table 4). Among smokers, $96.2 \%$ were asked their smoking status, $74.5 \%$ were ever advised to quit smoking, $21.9 \%$ were assessed of their readiness to quit, $14.2 \%$ received support to quit, and $2.7 \%$ were told to return to the clinic to follow up on their smoking ever during prenatal care. When we considered more than one visit, the percentages were $31.0 \%, 23.9 \%, 5.3 \%, 5.2 \%$, and $0.4 \%$ respectively. A much lower percentage of smokers received each step of the 5A's at all prenatal visits (Table 5). Since results were different by country, Tables 4 and 5 show the total numbers and the results by smoking status and country.

Among all quitters in both countries, the main reasons for quitting were being worried for the baby's health or because of being pregnant (79.8\%), being sick or having nausea (26.0\%), and being worried for their own health (12.0\%). In both countries less than $3 \%$ of all quitters reported that they quit due to advice from a health care professional, over half of women $(53.6 \%)$ reported thinking about their baby as the most helpful tool used to quit 
smoking and $11.5 \%$ reported chewing regular gum as a helpful cessation tools (data not shown).

As for women's intention to smoke in the postpartum period, overall $20.6 \%$ of smokers reported they were planning to smoke as usual after delivery, $31.1 \%$ were planning smoke less than before, $10.5 \%$ were not going to smoke and $37.8 \%$ were unsure. Among spontaneous quitters, $59 \%$ reported that they were not going to smoke and $40 \%$ were not sure. Among late quitters, $34 \%$ were not going to smoke and $61 \%$ were unsure. Since results were different by country, Table 6 shows the total numbers and the results by smoking status and country.

\section{Discussion}

Overall, nearly one out of three pregnant women participating in our study reported smoking at the time they got pregnant. This percentage is similar to estimates for women of reproductive ages in other high-income countries ${ }^{25-27}$ and higher than prevalence estimates in other Latin-American countries. ${ }^{7,28}$

National surveys implemented at each country from 2009 show that $19.8 \%$ of nonpregnant women in Uruguay and $22.4 \%$ in Argentina smoked. ${ }^{6,29}$ However, results from our study implemented in the capital cities of both counties show that $26.7 \%$ and $16.1 \%$ of women continued to smoke throughout pregnancy in Uruguay and Argentina, respectively. One difference to note is that our study was conducted in the capital cities, where rates of poverty are high, and may not be representative of the situation in the rest of the nation. It is unclear why the smoking prevalence is higher in Uruguay, despite the country's implementing population-based tobacco control measures since 2004. The difference in smoking prevalence by country was unexpected, and further research is needed to better understand these differences, particularly among low socioeconomic status pregnant women.

In any case these data highlight a serious public health concern and the need to eliminate tobacco use during pregnancy in Argentina and Uruguay. An economic evaluation of data provided in Argentina in 2011 estimated that the direct costs within the health system to attend to illness-related to smoking in the general population was \$2 $938556523 .^{30} \mathrm{In}$ Argentina and Uruguay, cost estimates for smoking during pregnancy are not currently available in order to motivate health systems to aggressively implement cessation strategies.

We also found that, on average in both countries, most women initiated smoking in adolescence, which suggests that prevention strategies aimed at youth are needed in addition to cessation interventions. Coordinated, multicomponent interventions that combine mass media campaigns, price increases, school-based policies and programs, and smoke-free policies are effective in reducing the initiation, prevalence and intensity of smoking among youth and young adults. ${ }^{31}$

We found that a best-practice approach to help pregnant smokers quit, the $5 \mathrm{~A}$ 's, was not fully implemented in the sample clinics as recommended by country cessation guidelines. As previously mentioned, national guidelines in both countries recommend that providers ask all pregnant women about their smoking status, advise them on the benefits of quitting, 
and provide assistance and follow-up for those who are ready to quit. While Argentina's guidelines recommend brief cessation counseling at every prenatal visit, Uruguay's guidelines do not specify the frequency. ${ }^{12,13}$ However, existence of guidelines does not necessarily imply a change in practice training all providers. ${ }^{32}$ Moreover, at the time of the current study, even if guidelines were published, neither Argentina nor Uruguay had yet conducted broad outreach and training to prenatal care providers. In both countries, low percentages of women reported that they were asked at more than one visit or every visit about their smoking status, and fewer were advised to quit smoking or given help to do so. This is similar to other studies where the first three As are more frequently implemented than the full 5A's. ${ }^{33-35}$ Available resources, even free ones like the quitline, ${ }^{12,13}$ were rarely provided. Some possible explanations could include lack of clinician training on the 5A's, lack of time to conduct the intervention during prenatal care, perceived resistance from women to quitting and concern about potential for harm to the relationship with the patient which has been reported in the formative research of our trial ${ }^{36}$ and in other studies conducted in high-income countries. ${ }^{37-39}$ A 2005 study of 300 obstetricians-gynecologists in Argentina showed that only $22 \%$ received training in smoking cessation counseling and $48.5 \%$ reported insufficient knowledge to provide smoking cessation advice. ${ }^{40}$ Similar implementation barriers were reported by midwives in the formative research of this project. ${ }^{41}$ Studies show that training on the 5A's as well as training in appropriate communication skills and patient-centered counseling methods such as motivational interviewing can improve smoking cessation. ${ }^{42}$ Thus, providing training, tools and resources on how to effectively implement the 5A's are needed. In addition, healthcare systems changes such as provider reminders and including the 5A's in electronic medical records may help to facilitate delivery of these interventions and integration into routine prenatal care. ${ }^{10}$ Moreover, tobacco use among physicians as in both countries their tobacco use is similar to that of the general population, which may hinder cessation guidelines implementation. ${ }^{43-45}$

Postpartum relapse to smoking may be of concern, considering $40 \%$ of women quit smoking during pregnancy and half of these women were unsure whether they would smoke after delivery. These women are in an advanced stage of change and should be a priority group for effective cessation strategies to prevent relapse and reduce secondhand smoke exposure among infants and children. ${ }^{24}$ Thus, education and relapse prevention messages (eg, adverse health effects of secondhand smoke exposure to infants and children) are needed, and prenatal intervention may need to be extended into the postpartum period to prevent relapse.

This study is not without limitations. First, receipt of the 5A's was based on retrospective, self-report. However, using responses from women who received the 5A's at more than one visit or all visits account reduce to recall bias. Validation was not possible as smoking cessation counseling was not typically documented in the clinical record in both countries. However, the majority of women maintained a card which documents all their prenatal care and women were allowed to refer to these cards when reflecting on their services. Second, due to limited resources, we relied on self-report to identify smoking status at the beginning of the pregnancy, and we were only able to biochemically verify smoking status of spontaneous and later quitters. However, misclassification of smoking status has been shown to be minimal among women who reported not smoking prior to pregnancy. ${ }^{18}$ Finally, these 
findings may not be generalizable beyond the study participants in these two countries, as the public hospitals and associated prenatal care clinics tend to serve lower-income women compared to private hospitals in these countries.

In conclusion, a substantial percentage of women continued to smoking during pregnancy in Buenos Aires and Montevideo; however, the 5A's is not being fully implemented by prenatal care providers, despite the existence of national recommendations. Efforts are needed to make available training, tools, and resources ${ }^{10}$ to encourage dissemination and implementation of the 5A's in prenatal care settings to help pregnant smokers quit smoking and to improve the health of both mother and infant.

\section{Acknowledgments}

The following investigators and institutions are part of the trial group and participated in the study: Principal Investigators-P. Buekens, F. Althabe; Trial Coordinating Unit-Argentina: F. Althabe, M. Berrueta, A. Mazzoni, P. Morello, A.Becu, L. Gibbons; Uruguay: A. Aleman, M. Colomar, L. Llambi, A. Ciganda; Formative-Research Team-M. Colomar; Tulane University School of Public Health and Tropical Medicine Team: P. Buekens, C. Johnson. Centers for Disease Control and Prevention Team: V. Tong, S. Farr, P. Dietz, R. Smith. Participating Hospitals and Staff-Argentina: Hospital Materno-Infantil Dr Carlos Gianantonio: D. Fernandez (coordinator), J. Carril; M. Rubino, M. Martinez (data managers); Hospital Zonal General de Agudos Heroes de Malvinas: J. Anton (coordinator), B. Clark, M. Rebotaro (data managers); Hospital General de Agudos Dr Carlos Bocalandro: E. Macagno (coordinator), N. Echarri, M. Munoz (data manager); Hospital Zonal General de Agudos Magdalena V. de Martinez: M. Ferrary (coordinator), C. Buttner (data manager); Instituto de Maternidad Santa Rosa: V. Nicolaci (coordinator) M. Colmenero, M. Debis, K. Ratel, V. Soraire, G. Alarcon (data manager); Hospital Zonal General de Agudos San Roque: M. T. Moreno (coordinator), S. Fernandez, G. Velazquez, M. Aguero (data manager); Hospital Zonal General de Agudos Dr Narciso Lopez: M. R. Sabbadin (coordinator); Hospital Zonal General de Agudos Evita Pueblo: S. Souza (coordinator), S. Perconti (data manager); Hospital Municipal Ostaciana B. de Lavignolle: C. Muzzio (coordinator), S. Rodriguez (data manager); Hospital Zonal General de Agudos Lucio Melendez: L. Frias (coordinator), B. Von Kaven (data manager). Uruguay-Administracion de los Servicios de Salud del Estado: O. Grana and E. Gomez; Banco de Prevision Social: A. Raggio. We would also like to acknowledge the CDC National Center for Environmental Health, Division of Laboratory Sciences for their support.

\section{Funding}

The study was supported through CDC cooperative agreement 5U48DP001948-04 (SIP09-18) to Tulane University. The findings and conclusions in this article are those of the authors and do not necessarily represent the official position of CDC.

\section{References}

1. World Health Organization. International Consultation on Environmental Tobacco Smoke (ETS) and Child Health. Geneva: Switzerland: World Health Organization; 1999. www.who.int/tobacco/ health_impact/youth/ets/en/print.html [Accessed March 10, 2015]

2. Centers for Disease Control and Prevention. How Tobacco Smoke Causes Disease: The Biology and Behavioral Basis for Smoking-Attributable Disease: A Report of the Surgeon General. Atlanta, GA: Centers for Disease Control and Prevention; 2010. www.ncbi.nlm.nih.gov/books/NBK53017/ [Accessed March 10, 2015]

3. Centers for Disease Control and Prevention. The Health Consequences of Smoking for Women. A Report of the Surgeon General. Atlanta, GA: Centers for Disease Control and Prevention; 2001. http://profiles.nlm.nih.gov/ps/access/NNBBRT.pdf [Accessed March 10, 2015]

4. Centers for Disease Control and Prevention. The Health Consequences of Smoking: A Report of the Surgeon General. Atlanta, GA: Centers for Disease Control and Prevention; 2004. www.cdc.gov/ tobacco/data_statistics/sgr/2004/index.htm [Accessed March 10, 2015]

5. Ministerio de Salud de la Nación. [Accessed March 10, 2015] GATS. Encuesta nacional de tabaquismo en adultos. Argentina. 2012. www.msal.gov.ar/ent/images/stories/vigilancia/pdf/ GATS_FactSheetARG_FINAL.pdf 
6. Ministerio de Salud de la Nación. [Accessed January 26, 2015] GATS. Encuesta nacional de tabaquismo en adultos. Uruguay. 2009. www.who.int/tobacco/surveillance/

fact_sheet_of_gats_uruguay_2010.pdf

7. Bloch M, Althabe F, Onyamboko M, et al. Tobacco use and secondhand smoke exposure during pregnancy: an investigative survey of women in 9 developing nations. Am J Public Health. 2008; 98(10):1833-1840. [PubMed: 18309125]

8. World Health Organization. WHO Recommendations for the Prevention and Management of Tobacco Use and Second-Hand Smoke Exposure in Pregnancy. Geneva, Switzerland: World Health Organization; 2013. www.who.int/tobacco/publications/pregnancy/ guidelinestobaccosmokeexposure/en/ [Accessed January 26, 2015Accessed January 26, 2015]

9. Chamberlain C, O'Mara-Eves A, Oliver S, et al. Psychosocial interventions for supporting women to stop smoking in pregnancy. Cochrane Database Syst Rev. 2013; 23(10):CD001055. CD001055.pub4. [PubMed: 24154953]

10. Fiore, MC.; Jaén, CR.; Baker, TB., et al. Treating Tobacco Use and Dependence:2008 Update. Clinical Practice Guidelines. U.S. Department of Health and Human Services. Public Health Service; 2008. www.ahrq.gov/professionals/clinicians-providers/guidelines-recommendations/ tobacco/clinicians/update/treating_tobacco_use08.pdf [Accessed July 7, 2015]

11. Everett-Murphy K, Steyn K, Mathews C, Petersen Z, et al. The effectiveness of adapted, best practice guidelines for smoking cessation counseling with disadvantaged, pregnant smokers attending public sector antenatal clinics in Cape Town, South Africa. Acta Obstet Gynecol Scand. 2010; 89(4):478-489. [PubMed: 20302533]

12. Guía Nacional de Tratamiento de la adicción al tabaco. [Accessed January 26, 2015] Ministerio de Salud y Ambiente de la Nación. Argentina. 2011. www.msal.gov.ar/tabaco/index.php/informacionpara-profesionales/cesacion-tabaquica

13. Ministerio de Salud Pública. Guía Nacional para el Abordaje del Tabaquismo: Uruguay. 2009 www.treatobacco.net/en/uploads/documents/Treatment\%20Guidelines/Uruguay\%20treatment \%20guidelines\%20in\%20Spanish\%202009.pdf.

14. Indicadores Básicos de Salud. Uruguay. 2013 www.msp.gub.uy/sites/default/files/ archivos_adjuntos/OPS\%20INDICADORES\%202013.pdf.

15. Secretaria de políticas, regulacióne institutos. [Accessed June 12, 2015] Dirección de estadísticas e información de salud, sistema estadístico de salud. Estadísticas vitales-Argentina-año. 2013. www.deis.msal.gov.ar/publicaciones/archivos/serie5nro57.pdf

16. Althabe F, Aleman A, Mazzoni A, et al. Tobacco cessation intervention for pregnant women in Argentina and Uruguay: study protocol. Reprod Health. 2013; 10(1):44. [PubMed: 23971512]

17. OpenClinica open source software, version 3.4.1. Waltham, MA, USA: Copyright ( $)$ OpenClinica LLC and collaborators; 2004-2015. www.OpenClinica.com [Accessed March 10, 2015]

18. England LJ, Grauman A, Quian C, et al. Misclassification of maternal smoking status and its effects on an epidemiologic study of pregnancy outcomes. Nicotine Tob Res. 2007; 9(10):10051013. [PubMed: 17852766]

19. Bernert JT, Turner WE, Pirkle JL, et al. Development and validation of a sensitive method for the determination of serum cotinine in both smokers and non-smokers by using liquid chromatography/atmospheric pressure ionization tandem mass spectrometry. Clin Chem. 1997; 43(12):2281-2291. www.clinchem.org/content/43/12/2281.full.pdf+html. [PubMed: 9439445]

20. Bernert JT, McGuffey JE, Morrison MA, Pirkle JL. Comparison of serum and salivary cotinine measurements by a sensitive high-performance liquid chromatography-tandem mass spectrometry method as an indicator of exposure to tobacco smoke among smoker and nonsmokers. J Anal Toxicol. 2000; 24(5):333-339. [PubMed: 10926356]

21. SRNT Subcommittee on Biochemical Verification. Biochemical verification of tobacco use and cessation. Nicotine Tob Res. 2002; 4(2):149-159. [PubMed: 12028847]

22. Tong VT, Althabe F, Alemán A, et al. The Prenatal Tobacco Cessation Intervention Collaborative. Accuracy of self-reported smoking cessation during pregnancy. Acta Obstet Gynecol Scand. 2015; 94(1):106-111. [PubMed: 25350478]

23. SAS Institute Inc. SAS: Version 9.3. Cary, NC: SAS Institute Inc; 2010. www.sas.com/en_us/ home.html [Accessed March 10, 2015] 
24. Tong VT, Morello P, Alemán A, et al. Pregnant women's secondhand smoke exposure and receipt of screening and brief advice by prenatal care providers in Argentina and Uruguay. Matern Child Health J. 2015; 19(6):1376-1383. [PubMed: 25427876]

25. Egebjerg Jensen K, Jensen A, Nøhr B, Krüger Kjaer S. Do pregnant women still smoke? A study of smoking patterns among 261,029 primiparous women in Denmark 1997-2005. Acta Obstet Gynecol Scand. 2008; 87(7):760-767. [PubMed: 18696277]

26. Lelong N, Blondel B, Kaminski M. Smoking during pregnancy in France between 1972 to 2003: results from the national perinatal surveys. J Gynecol Obstet Biol Reprod (Paris). 2011; 40(1):4249. [PubMed: 20864276]

27. Jiménez-Muro A, Samper MP, Marqueta A, Rodríguez G, Nerín I. Prevalence of smoking and second-hand smoke exposure: differences between Spanish and immigrant pregnant women. Gac Sanit. 2012; 26(2):138-144. [PubMed: 22000865]

28. World Health Organization. [Accessed March 10, 2015] Tobacco Free Initiative (TFI). Tobacco control country profiles. 2013. www.who.int/tobacco/surveillance/policy/country_profile/en/

29. Ministerio de Salud de la Nación. Segunda Encuesta Nacional de Factores de Riesgo para enfermedades no trasmisibles. Buenos Aires, Argentina: Ministerio de Salud de la Nación; 2011. www.msal.gov.ar/ent/index.php/vigilancia/areas-de-vigilancia/factores-de-riesgo [Accessed March 10, 2015]

30. Pichon-Riviere A, Augustovski F, Bardach A, et al. Tobacco Research Group. Development and validation of a microsimulation economic model to evaluate the disease burden associated with smoking and the cost-effectiveness of tobacco control interventions in Latin America. Value Health. 2011; 14 suppl 1(5):S51-S59. [PubMed: 21839900]

31. Centers for Disease Control and Prevention. Preventing Tobacco Use Among Youth and Young Adults: A Report of the Surgeon General. Atlanta, GA: Centers for Disease Control and Prevention; 2012. www.surgeongeneral.gov/library/reports/preventing-youth-tobacco-use/fullreport.Pdf [Accessed March 10, 2015]

32. Perlen S, Brown SJ, Yelland J. Have Guidelines about smoking cessation support in pregnancy changed practices in Victoria, Australia? Birth. 2013; 40(2):81-87. [PubMed: 24635461]

33. Chase EC, McMenamin SB, Halpin HA. Medicaid provider delivery of the 5A's for smoking cessation counseling. Nicotine Tob Res. 2007; 9(11):1095-1101. [PubMed: 17978983]

34. Quinn VP, Hollis LF, Smith KS, et al. Effectiveness of the 5-As tobacco cessation treatments in nine HMOs. J Gen Intern Med. 2009; 24(2):149-154. [PubMed: 19083066]

35. Stevens VJ, Solberg LI, Quinn VP, et al. Relationship between tobacco control policies and the delivery of smoking cessation services in nonprofit HMOs. J Natl Cancer Inst Monogr. 2005; (35): 75-80. [PubMed: 16287890]

36. Colomar M, Tong V, Morello P, et al. Barriers and promoters of an evidenced-based smoking cessation counseling during prenatal care in Argentina and Uruguay. Matern Child Health J. 2015; 19(7):1481-1489. [PubMed: 25500989]

37. Nichter M, Nichter M, Muramoto M, et al. Smoking among low-income pregnant women: an ethnographic analysis. Health Educ Behav. 2007; 34(5):748-764. [PubMed: 17200098]

38. Beenstock J, Sniehotta FF, White M, Bell R, Milne EM, Araujo-Soares V. What helps and hinders midwives in engaging with pregnant women about stopping smoking? A cross-sectional survey of perceived implementation difficulties among midwives in the North East of England. Implement Sci. 2012; 7:36. [PubMed: 22531641]

39. Baxter, S.; Blank, L.; Guillaume, L., et al. Systematic Review of How to Stop Smoking in Pregnancy and Following Childbirth. Review 2: Factors Aiding Delivery of Effective Interventions. Sheffield, United Kingdom: The University of Sheffield School of Health and Related Research; 2009. www.nice.org.uk/guidance/ph26/evidence/quitting-smoking-inpregnancy-andfollowing-childbirth-systematic-review2 [Accessed June 12, 2015]

40. Mejia R, Buil Martinez V, Gregorich S, Pérez-Stable EJ. Physician counseling of pregnant women about active and second hand smoking in Argentina. Acta Obstet Gynecol Scand. 2010; 89(4): 490-495. [PubMed: 20367427] 
41. Belizan M, Meier A, Althabe F, et al. Facilitators and barriers to adoption of evidence-based perinatal care in Latin American hospitals: a qualitative study. Health Educ Res. 2007; 22(6):839_ 853. [PubMed: 17395605]

42. Borrelli B, Lee C, Novak S. Is provider training effective? Changes in attitudes towards smoking cessation counseling and counseling behaviors of home health care nurses. Prev Med. 2008; 46(4): 358-363. [PubMed: 17950452]

43. Salgado M, Mejia R, Kaplan C, et al. Smoking behavior and use of tobacco industry sponsored websites among medical students and young physicians in Argentina. J Med Internet Res. 2014; 16(2):e35. [PubMed: 24509433]

44. Gigliotti E, Ferrero F, Castanos C, et al. Study group on smoking among pediatric residents. Tobacco consumption among pediatric residents in Argentina. Current prevalence and trend over the past 10 years. Arch Argent Pediatr. 2013; 111(4):315-321. [PubMed: 23912289]

45. Llambí L, Barros M, Parodi C, et al. Conocimientos, creencias, prácticas y actitudes con respecto al consumo de tabaco de estudiantes de Medicina de primer año en Uruguay, 2009. Rev Méd Urug. 2012; 28(1):4-12. www.rmu.org.uy/revista/2012v1/art2.pdf. 


\section{올 \\ 골}

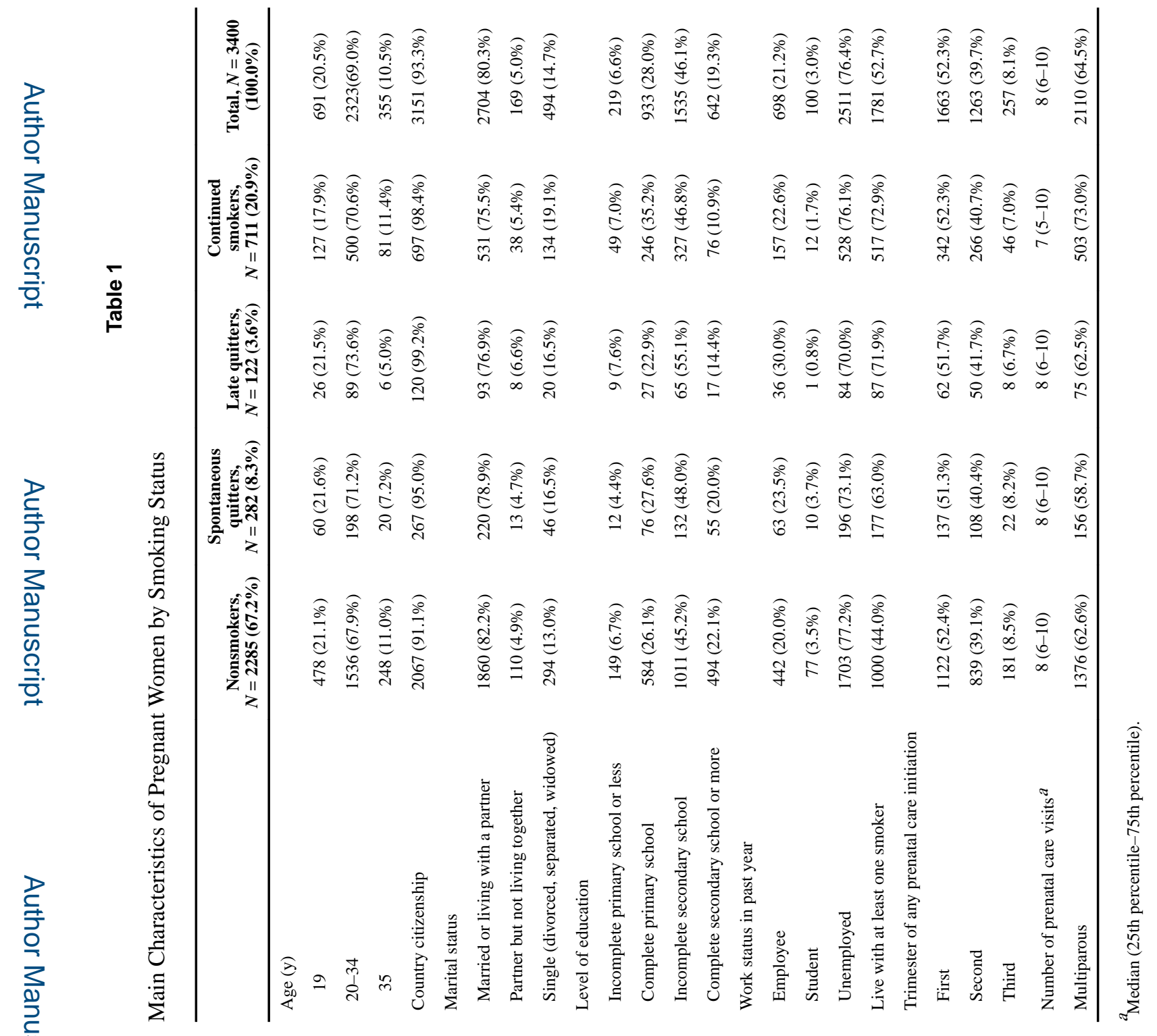

Nicotine Tob Res. Author manuscript; available in PMC 2017 May 01. 
Berrueta et al.

\section{을 \\ 골}

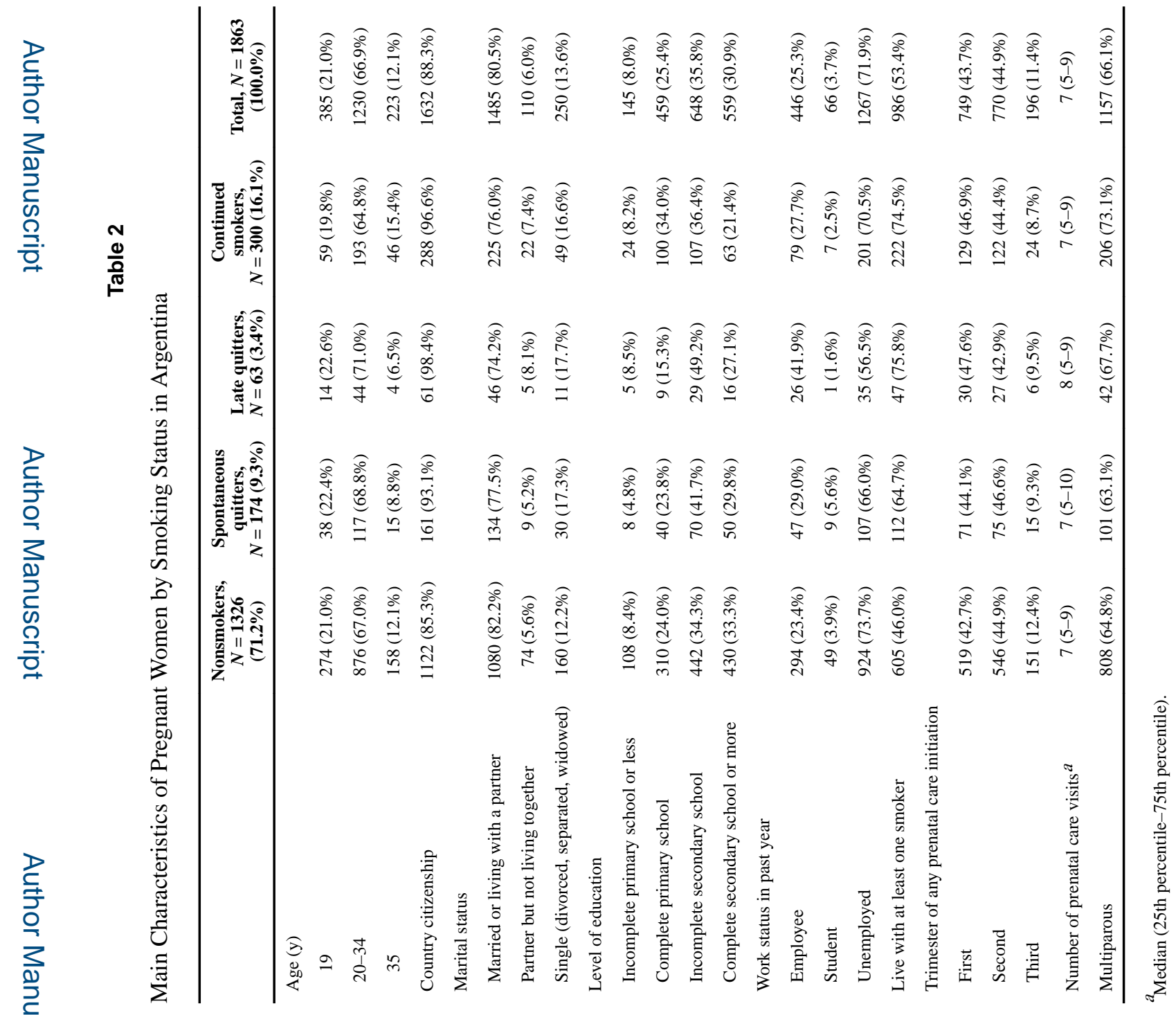

Nicotine Tob Res. Author manuscript; available in PMC 2017 May 01. 
Berrueta et al.

\section{竞 \\ 골}

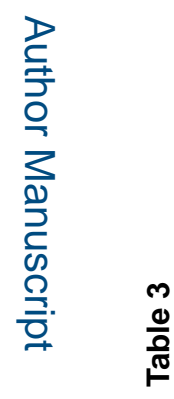

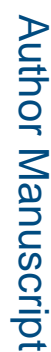

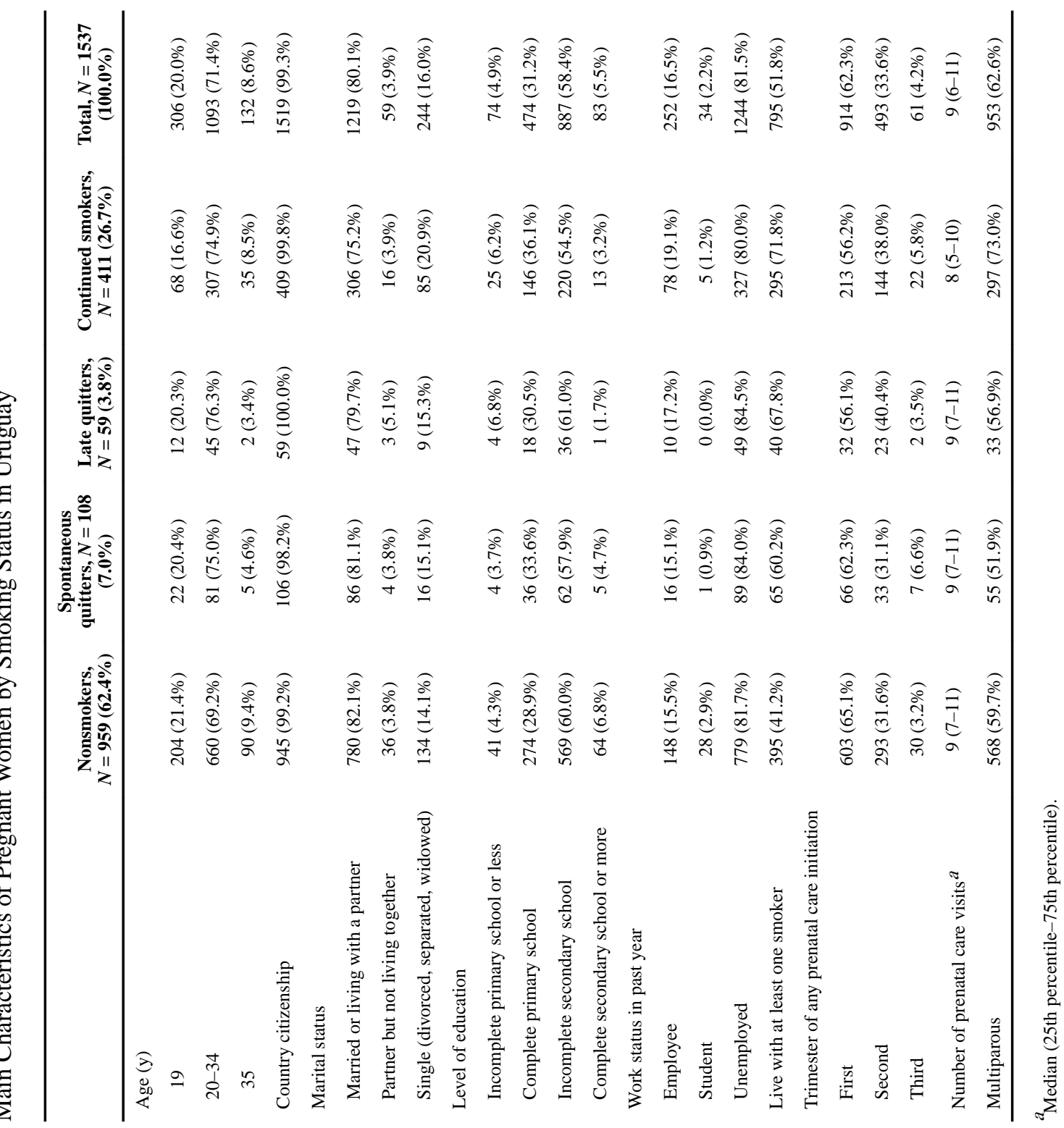

Nicotine Tob Res. Author manuscript; available in PMC 2017 May 01. 


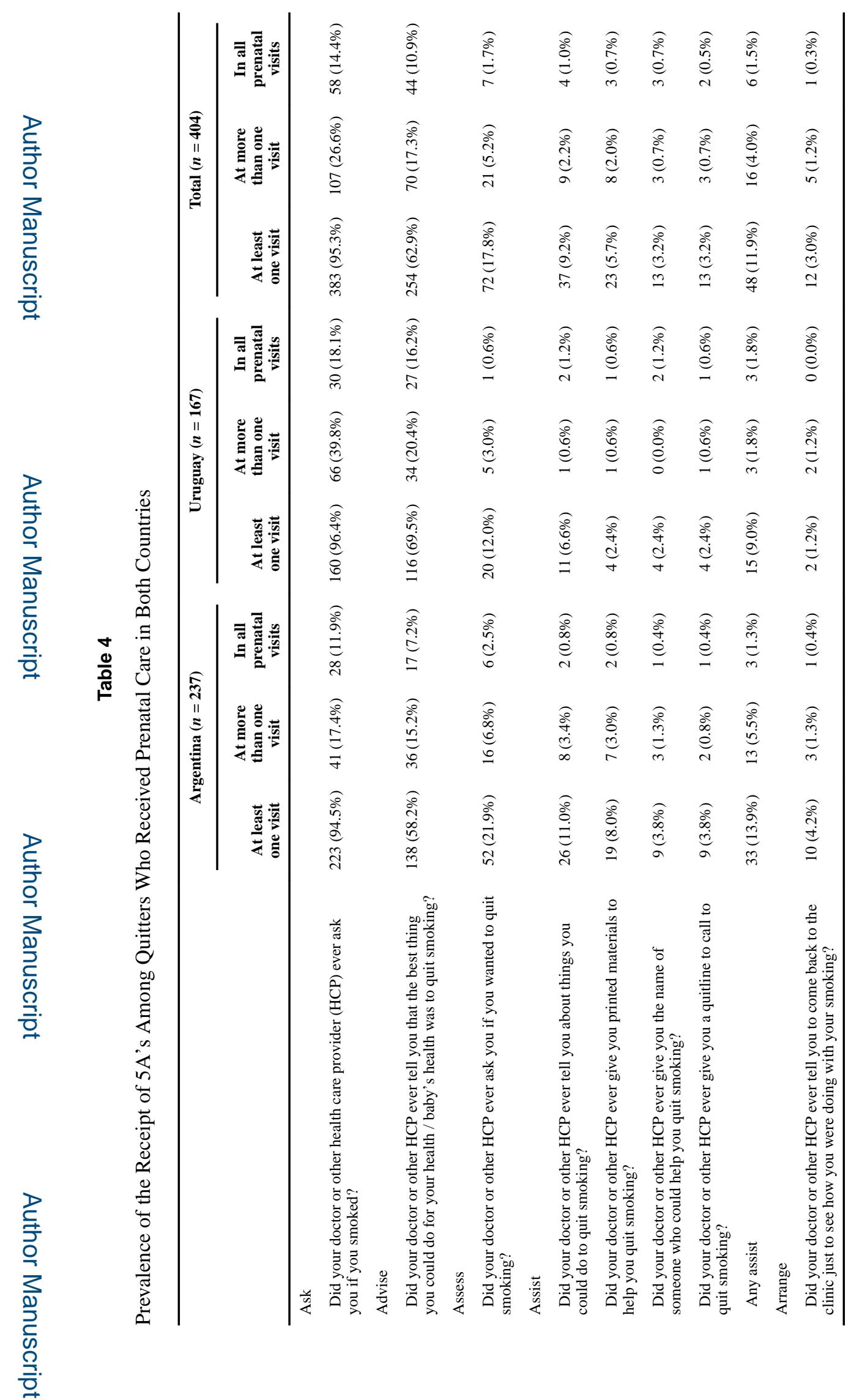

Nicotine Tob Res. Author manuscript; available in PMC 2017 May 01. 


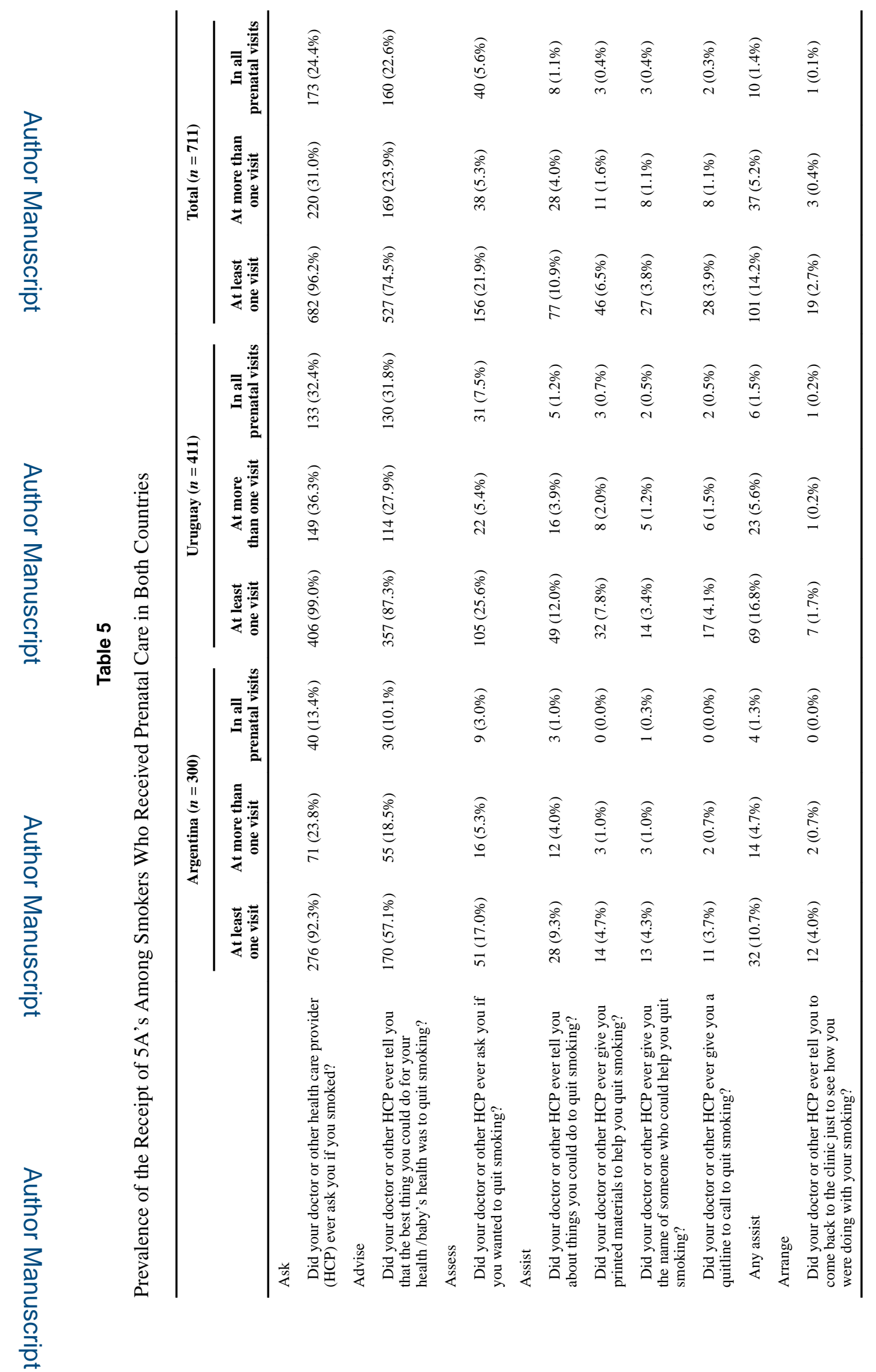

Nicotine Tob Res. Author manuscript; available in PMC 2017 May 01. 


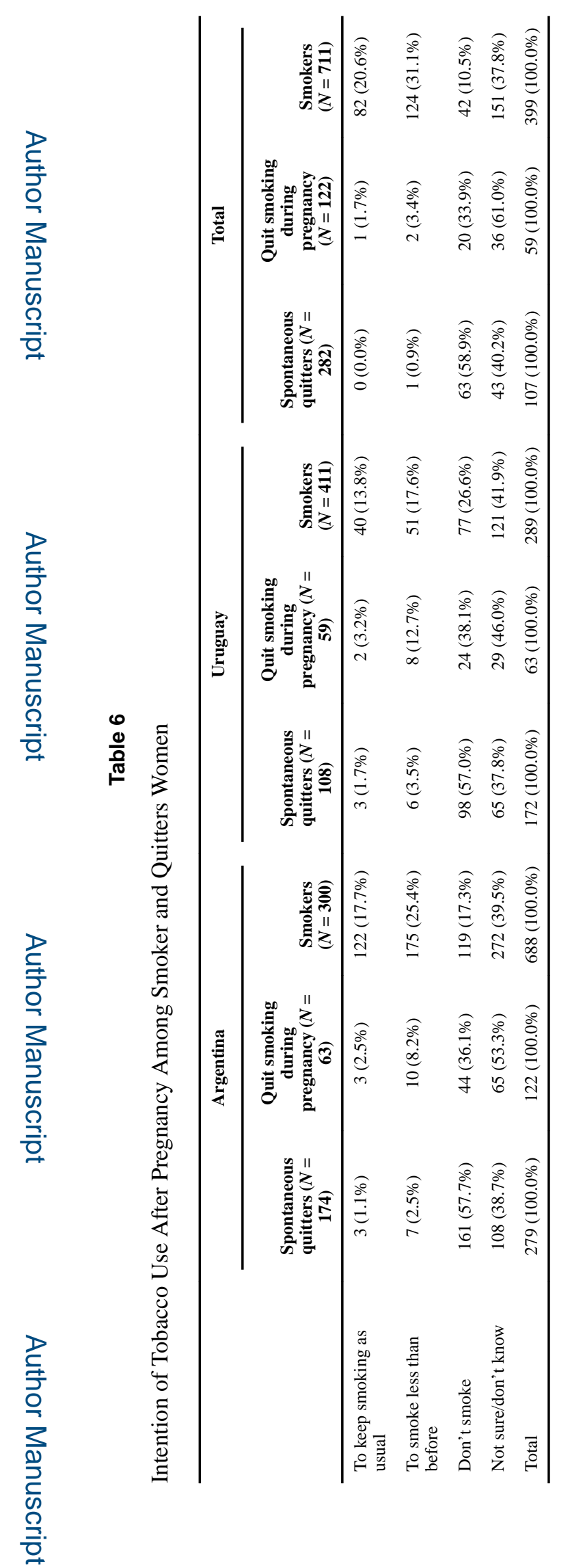

Nicotine Tob Res. Author manuscript; available in PMC 2017 May 01. 